\title{
Paleomagnetic and Anisotropy of Magnetic Susceptibility (AMS) analyses of the Plio-Pleistocene extensional Todi basin, Central Italy
}

\author{
Laura Alfonsi \\ Istituto Nazionale di Geofisica, Roma, Italy
}

\begin{abstract}
In the last few years paleomagnetic investigations within the Apennine chain have revealed that the area is characterized by a complex pattern of deformation, not linkable to a simple and homogeneous process. In order to estimate the amount, sense and timing of vertical axis rotations within the Central Apennines, Neogene continental basins have been investigated for paleomagnetic studies. The paleomagnetic results obtained in the Plio-Pleistocene Todi basin showed that the Upper Pliocene-Lower Pleistocene evolution, associated with major dip-slip tectonics, has not involved vertical axis rotation since that time. The Anisotropy of Magnetic Susceptibility analysis (AMS), carried out on the same samples treated for paleomagnetic determination, revealed the presence of two groups of specimens characterized by different magnetic lineation directions. One direction trends NE-SW and is parallel to the orientation of the regional extension stress typical of the area. This direction is observed throughout the northern basin. The other, restricted to the southern basin, trends N-S and shows no links with the tectonic, hydrological-sedimentary conditions of the area. The results of the AMS analysis will be presented and discussed in the light of the rock magnetic results and the tectonic framework of the area.
\end{abstract}

Key words Apennines - paleomagnetism anisotropy of magnetic susceptibility

\section{Introduction}

Cretaceous to Upper Miocene paleomagnetic data obtained within the Central Apennines indicate a non homogeneous and strongly structure-dependent amount and sense of vertical axis rotations (e.g., Jackson, 1990; Marton and D'Andrea, 1992; De La Pierre et al., 1992; Mattei et al., 1995). Plio-Pleistocene paleomagnetic data from localities in Central and

Mailing address: Dr. Laura Alfonsi, Istituto Nazionale di Geofisica, Via di Vigna Murata 605, 00143 Roma, Italy; e-mail: alfonsi@ing750.ingrm.it
Southern Italy (e.g., Aifa et al., 1988, Scheepers and Langerais, 1993; Sagnotti et al., 1994) revealed that the deformations affecting the Italian peninsula after the Late Tortonian time $(8 \mathrm{Ma})$ could not be associated with a single process, as previously stated (Patacca et al., 1990; Doglioni, 1991; Castellarin et al., 1992).

Though differences in amount, style and timing of the Neogene deformation are observable by geological and geophysical means across the Italian peninsula (e.g., CNR, 1989), their quantification is still lacking. Plio-Pleistocene paleomagnetic data can contribute to constrain these differences, and clear up the recent geodynamic evolution of the Tyrrhenian Sea-Apennine chain system. In this paper, the Plio-Pleistocene sediments of the Tiberian extensional basin, Central Italy, are the object of 
paleomagnetic investigations. A characteristic and well defined remanent magnetisation was isolated from Upper Pliocene-Lower Pleistocene sediments, and found to parallel the direction of the contemporary Earth's magnetic field at the sampled locality. The SW sector of the «Bacino Tiberino» (Todi basin), dominated by major vertical tectonics, has not experienced rotations around the vertical axis since Upper Pliocene time.

This paper also presents the results of the Anisotropy of Magnetic Susceptibility (AMS), carried out in the same localities treated for paleomagnetic determination. The AMS has various applications in Earth science studies; it has been widely employed for petrofabric determination to investigate strain and flow planes in rocks (e.g., Lowrie and Hirt, 1987; Hrouda, 1982; Tarling and Hrouda, 1993). The AMS is commonly expressed by an ellipsdoid, whose principal axes are $K_{\max } \geq K_{\mathrm{int}} \geq K_{\min }$. The shape of the AMS ellipsoid is related to the rock fabric, that is to say to the distribution and shape of magnetic grains in a sediment. The AMS results in general from the alignment of magnetocrystalline preferable axes and/or of the elongated shapes of ferrimagnetic grains in a rock, which is related to processes affecting the sediment during deposition. The hydrological, tectonic, igneous process can lead to a particular alignment of the AMS ellipsoid axes. In deformed sedimentary rocks the AMS is closely related to their strain ellipsoids (e.g., Graham, 1966, Kligfield et al., 1981). It has been shown, for different structural settings and rock types, that during the early stages of deformation the $K_{\max }$ axis will align in the bedding plane roughly perpendicular to the direction of maximum shortening, while the $K_{\min }$ parallels the bedding pole (e.g., Lowrie, 1989). The AMS of weakly deformed sediments confirmed the parallelism between the susceptibility and strain axes (Kissel et al., 1986; Lee et al., 1990; Sagnotti and Speranza, 1993). The Plio-Pleistocene continental sediments of the Todi, Bastardo and Bevagna basins (Central Italy) have been the object of AMS studies.

The AMS and the rock magnetic analyses allow the whole set of analysed samples to be divided into two groups characterised by dif- ferently oriented magnetic lineations. One direction trends NE-SW and is characteristic of the northern section of the basin, and the other is N-S aligned and is typically found in the southern part of the basin (see fig. 1). This grouping is partially reflected in the rock magnetic analyses: the sites showing the NE-SW magnetic lineation have magnetite as the main magnetic carrier, and the rock magnetic analyses showed that the paramagnetic phases are responsible for the AMS observations in the north of the basin. Instead the samples with the $\mathrm{N}-\mathrm{S}$ magnetic lineation, restrained at the south of the basin, are characterised mainly by ironsulphide minerals. A thermal destructive test was then applied to the latter samples to speculate the role of the ferrimagnetic content on the magnetic lineation. The procedure of the test is shown in this paper. The conclusive results are not straightforward for all sites of the southern basin, and the iron-sulphides could not be claimed to be solely responsible for the N-S lineation observed at the southern part of the basin.

\section{Geological setting}

The Todi, Bastardo and Bevagna basins, about $100 \mathrm{~km}$ north of Rome in the Umbria region (fig. 1), are part of an intra-montane depression, the «Bacino Tiberino», which developed during the Neogene and Quaternary extensional processes that dissected the Apennine range (see, e.g., Parotto and Praturlon, 1975, for a review). The analysed sediments of the Todi basin are continental and could be grouped into five units ranging in age from Upper Pliocene (Lower Villafranchian) to Lower Pleistocene. Their lithologies are mainly sandy silts or sandy clays sometimes interbedded with lignites (Conti and Girotti, 1977; Ambrosetti et al., 1972); sheet floods are the typical depositional processes of these sediments (Ambrosetti and Basilici, 1994). Lower Pleistocene travertines of hydrothermal origin crop out predominantly in the southern part of the basin, where contemporaneous ultra-alkaline rocks are also present $(0.39 \mathrm{Ma}$; Lavecchia and Stoppa, 1990). These occur near the N-S ori- 


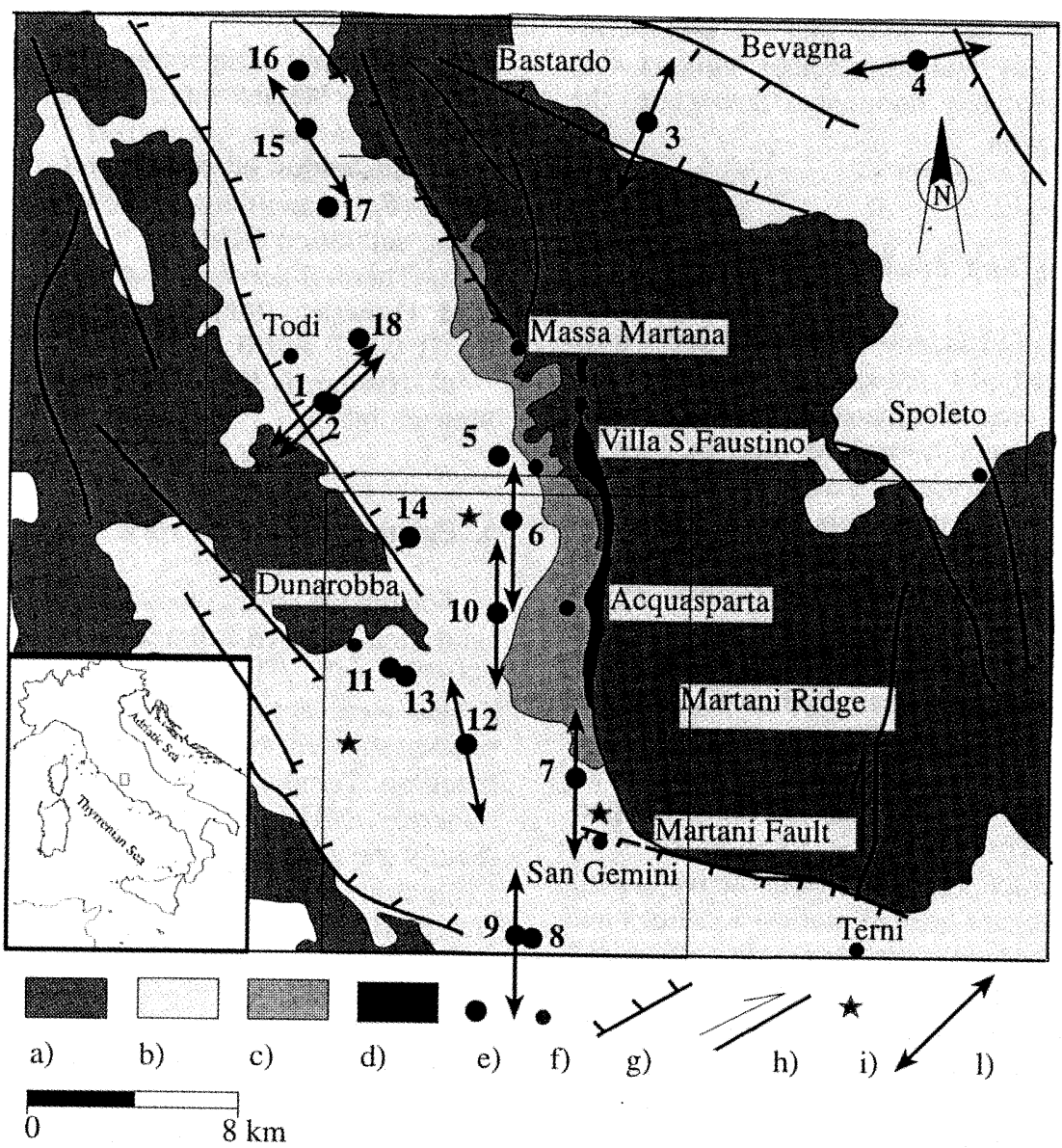

Fig. 1. Simplified geological and structural map of the study area. a) Meso-Cenozoic sediments; b) PlioPleistocene units (undifferentiated); c) travertines; d) ultra-alkaline volcanic products; e) sampling localities; f) villages; g) normal dip-slip faults; h) strike-slip faults; i) mineral springs and active fumaroles; 1) direction of the magnetic lineation.

ented tectonic structures, characterised by dipslip and transtentional mechanisms, and are linked to phreato-magmatic activity (fig. 1; Brozzetti et al., 1991). Even today mineral springs and low-temperature fumaroles are locally active. The depositional environment of the small Bastardo and Bevagna basins, located $15 \mathrm{~km}$ east of the Todi basin, was instead marsh-like. The age of their argillaceous and lignite sediments has been constrained at around 1.0 Ma (Gregori, 1988).
Measurements of borehole breakouts in deep wells nearby (Vulsini hills, nearly $80 \mathrm{~km}$ north-west of the Todi basin; see, e.g., Montone et al., 1995) indicate a contemporary NEENE direction of the least compressive stress $\left(\mathrm{SH}_{\mathrm{min}}\right)$. This orientation is also evident from $T$ axes directions determined from focal mechanism inversions (Montone et al., 1995). Geological and structural extensional elements of NE-ENE affected the basin in Plio-Pleistocene time (Conti and Girotti, 1977; Ambrosetti and 
Basilici, 1994) suggesting that the present direction of the least horizontal compressive stress had probably dominated throughout the life of the basin.

\section{Sampling and measurements}

The Plio-Pleistocene continental units have been selected for paleomagnetic and AMS analysis. At least 8 oriented cores were drilled in situ at 18 sampled localities (fig. 1). Two localities (T1, T2) are of Lower Villafranchian age (Pliocene), all the others are of Upper Villafranchian (Lower Pleistocene) age (Conti and Girotti, 1977; Ambrosetti and Basilici, 1994). Seven sites were sampled in the northern part of the Todi basin (T1, T2, T5, T15, T16, T17, T18). Nine sites were sampled in the southern part of the basin (T6, T7, T8, T9, T10, T11, T12, T13, T14). Two sites are located in the small basins of Bastardo and Bevagna (respectively T3, T4).

Faults which probably were active during sedimentation are present at most localities and are consistent with the stress directions discussed previously. Unlike samples from the northern part of the basin, samples collected from the southern part are all within $10 \mathrm{~km}$ from calc-alkaline volcanic rocks and modern mineral springs and fumaroles (fig. 1).

Laboratory measurements were carried out in a magnetically shielded room at the paleomagnetic laboratory of the Istituto Nazionale di Geofisica, Rome. For the AMS measurements a Kly-2 bridge was utilized; the evaluation of the AMS tensor was made through measurements along fifteen different directions (Jelìnek, 1977). The mean susceptibility tensor for any given site was computed using Jelìnek (1978) statistics. A JR-5 magnetometer was employed for the Natural Remanent Magnetisation (NRM) measurements. The stepwise thermal demagnetisation for the whole set of samples was then obtained on an electrical shielded oven. The AF treatment was done on a Molspin AF demagnetizer.

The magnetic mineralogy of the samples was determined at least on one specimen per site, by:

a) Stepwise acquisition of an Isothermal Remanence Magnetisation (IRM) up to $1.6 \mathrm{~T}$, employing a pulse magnetizer.

b) Evaluation of the coercivity of the remanence $\left(B_{0} c r\right)$ applying an increasing back-field to the saturation IRM.

c) Thermal demagnetisation of a composite IRM (Lowrie, 1990), produced in fields of $1.6 \mathrm{~T}, 0.6 \mathrm{~T}$ and $0.12 \mathrm{~T}$.

d) Hysteresis loops on a Vibrating Sample Magnetometer.

\section{Paleomagnetic and rock magnetic results}

For the set of analysed samples, $90 \%$ of the saturation magnetisation was reached between 200-500 $\mathrm{mT}$. The coercivity of remanence values were around $-50 \mathrm{mT}$. The coercivity phases showed two different Maximum Unblocking Temperatures (MUT). Iron-sulphide minerals (MUT of $300-360^{\circ} \mathrm{C}$ ) characterised mainly the soft and medium coercivity phases. Magnetite (blocking temperature of $580^{\circ} \mathrm{C}$ ) was carried by the soft coercivity phases. Figure $2 \mathrm{a}$,b shows two typical behaviours of the demagnetisation of the three artificially imparted IRM. Both values of the unblocking temperatures were present at six sites (T2, T7, T8, T9, T10, T11). Magnetite was the only magnetic carrier at three sites (T4, T15, T17), see also table I.

High values of the NRM intensities and of the interparametric ratio SIRM/k (e.g., Snowball, 1991) were typical of the samples containing ferrimagnetic iron-sulphides (330$360{ }^{\circ} \mathrm{C}$ maximum unblocking temperature, although this does not hold for site T6). The samples containing iron-sulphides showed a significant decrease of the low field susceptibility between $200-300{ }^{\circ} \mathrm{C}$ during thermal demagnetisation, as typical of iron-sulphides minerals (Roberts and Pillans, 1993). On the contrary, where only magnetite was present lower NRM and SIRM/k values were observed (T4, T15, T17). Table I illustrates the rock magnetic results.

Two pilot specimens for each site were thermally and AF demagnetised. The thermal 


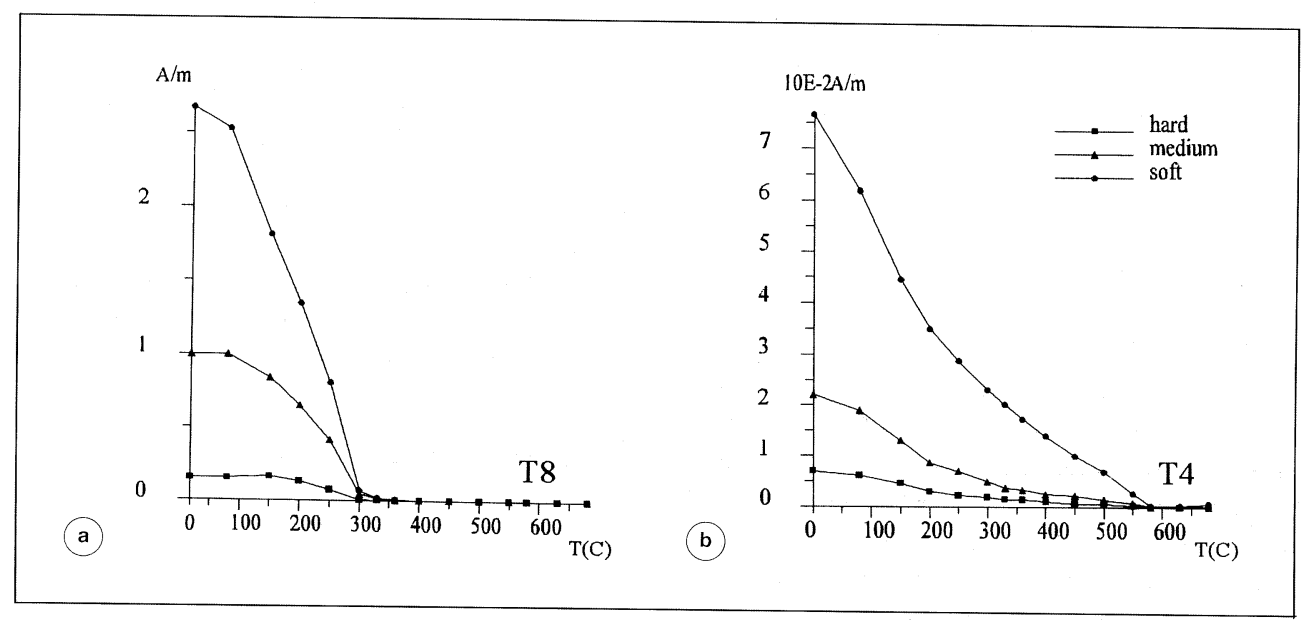

Fig. 2a,b. Typical magnetic properties of two representative specimens: a) thermal demagnetisation of a three component IRM for a sample containing iron-sulphides; b) thermal demagnetisation of a three component IRM for a sample containing magnetite.

Table I. Rock magnetic parameters. NRM = Natural Remanent Magnetization; $K=$ mean low-field magnetic susceptibility; SIRM $=$ Saturation Isothermal Remanent Magnetization; $B_{0}(c r)=$ coercivity of remanance; $T b=$ maximum unblocking temperature.

\begin{tabular}{lcccccc}
\hline \hline Sample & $\begin{array}{c}\mathrm{NRM} \\
\mathrm{A} / \mathrm{m}\end{array}$ & $\begin{array}{c}K \\
10^{-6} \mathrm{SI}\end{array}$ & $\begin{array}{c}\mathrm{SIRM} \\
\mathrm{A} / \mathrm{m}\end{array}$ & $\begin{array}{c}B_{0}(\mathrm{cr}) \\
\mathrm{mT}\end{array}$ & $T b^{\circ} \mathrm{C}$ & $\begin{array}{c}\text { SIRM/K } \\
\mathrm{kA} / \mathrm{m}\end{array}$ \\
\hline T1-10C & $6.82 \times 10^{-5}$ & 182 & $6.28 \times 10^{-2}$ & -41 & $580^{\circ}$ & 0.35 \\
T2-3A & $2.92 \times 10^{-4}$ & 154 & $2.1 \times 10^{-1}$ & -66 & $360-580^{\circ}$ & 1.3 \\
T3-10C & $6.12 \times 10^{-5}$ & 136 & $5.66 \times 10^{-2}$ & -47 & $580^{\circ}$ & 0.43 \\
T4-4C & $3.64 \times 10^{-4}$ & 157 & $8.19 \times 10^{-2}$ & -45 & $580^{\circ}$ & 0.53 \\
T5-10C & $4.51 \times 10^{-5}$ & 156 & $4.11 \times 10^{-2}$ & -42 & $580^{\circ}$ & 0.27 \\
T6-8B & $4.24 \times 10^{-6}$ & 185 & $3.45 \times 10^{-2}$ & -42 & $360-580^{\circ}$ & 0.19 \\
T7-1B & $4.66 \times 10^{-3}$ & 264 & $1.35 \times 10^{1}$ & -63 & $360^{\circ}$ & 53 \\
T8-11B & $1.64 \times 10^{-2}$ & 699 & $2.24 \times 10^{1}$ & -55 & $360^{\circ}$ & 34 \\
T9-7A & $3.44 \times 10^{-4}$ & 131 & $4.84 \times 10^{-2}$ & -52 & $360-580^{\circ}$ & 0.38 \\
T10-2B & $5.89 \times 10^{-3}$ & 221 & 2.08 & -50 & $360-580^{\circ}$ & 9.59 \\
T11-8C & $8.99 \times 10^{-4}$ & 128 & $6.89 \times 10^{-1}$ & -112 & $360-580^{\circ}$ & 5.4 \\
T11-6A & $6.86 \times 10^{-5}$ & 128 & $1.03 \times 10^{-1}$ & -51 & $580^{\circ}$ & 0.83 \\
T12-3A & $1.31 \times 10^{-5}$ & 197 & $3.97 \times 10^{-2}$ & -47 & $580^{\circ}$ & 0.21 \\
T13-8A & $8.10 \times 10^{-5}$ & 147 & $1.37 \times 10^{-1}$ & -76 & $360-580^{\circ}$ & 0.93 \\
T14-4B & $8.46 \times 10^{-5}$ & 136 & $7.70 \times 10^{-2}$ & -50 & $360-580^{\circ}$ & 0.6 \\
T15-1A & $1.10 \times 10^{-5}$ & 152 & $2.11 \times 10^{-1}$ & -47 & $580^{\circ}$ & 1.3 \\
T16-7A & $5.10 \times 10^{-5}$ & 167 & $7.11 \times 10^{-2}$ & -45 & $580^{\circ}$ & 0.43 \\
T17-7A & $2.79 \times 10^{-4}$ & 103 & $1.06 \times 10^{-1}$ & -50 & $580^{\circ}$ & 0.99 \\
T18-6A & $4.65 \times 10^{-5}$ & 166 & $6.04 \times 10^{-2}$ & -42 & $580^{\circ}$ & 0.37 \\
\hline
\end{tabular}


treatment produced a more efficient magnetic cleaning at most of the sites (T7, T8, T9, T10, T11, T15, T17). Only two sites underwent AF magnetic cleaning (T2, T4). The NRM values of the other sites were too weak to be properly measured (T1, T3, T5, T6, T12, T13, T16, T18). The behaviour of the low field magnetic susceptibility was monitored at each heating step, checking for changes in the magnetic mineralogy.

Both linear paths and remagnetisation circles were obtained from the analysed specimens, and they were generally well defined (fig. 3a,b). Magnetic directions of individual samples were determined using principal component analysis (Kirschvink, 1980), considering samples having maximum angular dispersion values lower than $10^{\circ}$. Site mean directions, obtained by combining linear path and remagnetisation circles, were computed using McFadden and McElhinny (1988) statistics.

At nine sites a stable and well defined component of magnetisation was isolated (T2, T4, T7, T8, T9, T10, T11, T15, T17). The averaged NRM intensities for these sites ranged from
$1.1 \times 10^{-5}$ to $1.6 \times 10^{-2} \mathrm{~A} / \mathrm{m}$. A Low Temperature component (LT) characterised four sites (T7, T8, T10, T11). This was stable up to $400{ }^{\circ} \mathrm{C}$ and had a reverse polarity (fig. 4a). Two sites (T15, T17) show a normal polarity LT component obtained by combining linear paths and remagnetisation circles defined up to $180-220^{\circ} \mathrm{C}$ (fig. 4c). A High Temperature component (HT) was also observed in five specimens at two sites (T7, T11). This latter component was not stable and the intersection point of the remagnetisation circles showed a mean direction antiparallel to the mean LT component observed at the same sites (fig. 4b). Within the sites AF demagnetised, T2 showed a stable component, reverse in polarity, once the soft coercivity phase was removed; site T4 showed only one component of magnetisation stable up to $250 \mathrm{mT}$, normal in polarity. At all the analysed sites the LT component accounted for $80-90 \%$ of the total NRM intensities; the HT component, when observed, contributed only about $15-20 \%$ of the total NRM. Table II gives a summary of the paleomagnetic determinations.

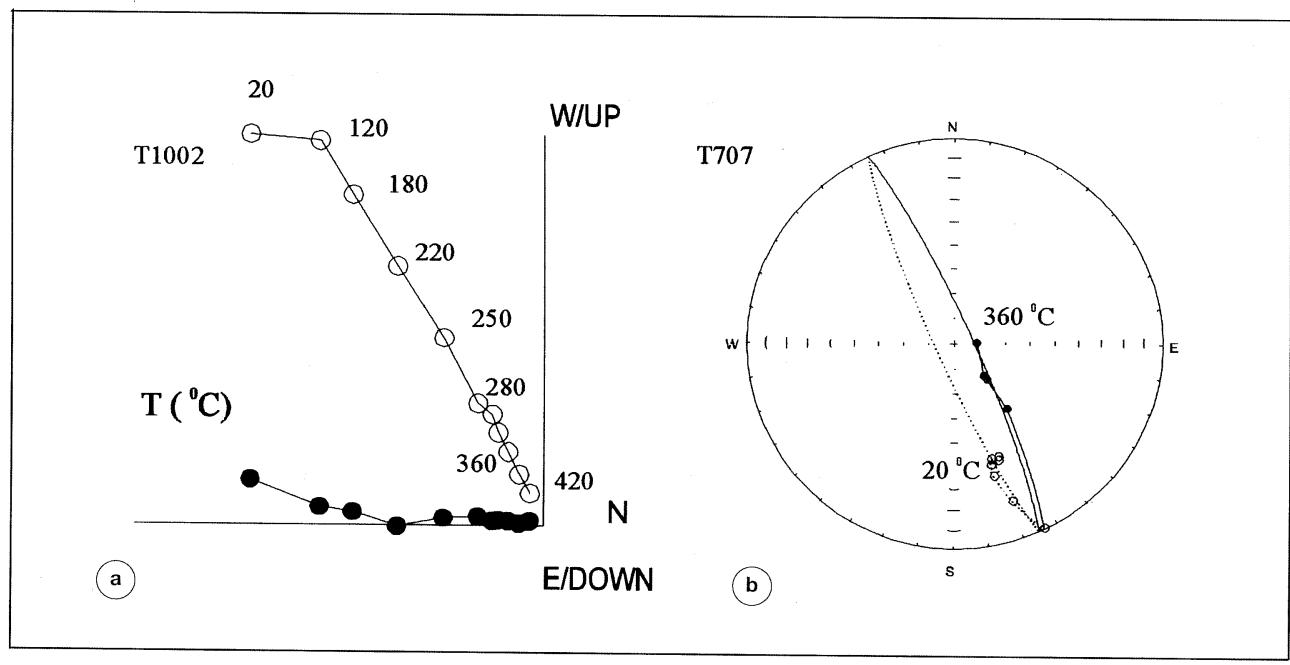

Fig. 3a,b. Representative demagnetisation plots after tectonic correction. a) Orthogonal projection of thermal demagnetisation data for a specimen showing a single stable component of magnetisation. Open circles: vertical projection; full circles: horizontal projection. b) Remagnetisation circles of a thermally demagnetised specimen. Solid lines and full circles: lower hemisphere; open cirlces and dashed lines: upper hemisphere. 


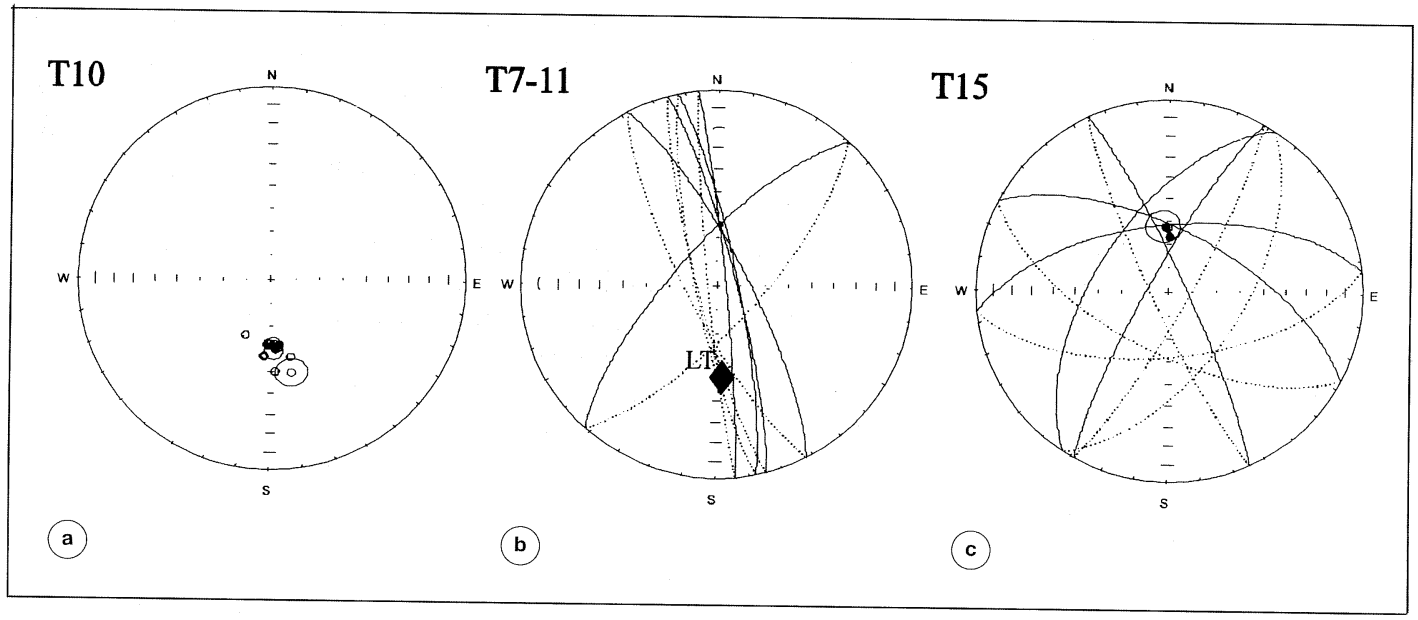

Fig. 4a-c. Equal area projection for three representative cases: a) stable directions; b) remagnetisation circles departing from an LT component for five representative specimens characteristic of two sampling sites (T7, T11), the diamond represents the site mean direction of the LT component characteristic of the same sites; c) stable direction and great circles.

Table II. Treat. $=$ demagnetization treatment; $N=$ number of analysed specimens (1: number of linear paths; c: number of remagnetization circles); $D, I=$ declination and inclination before tectonic correction; $A=$ azimuth of dip; Dip = dip of bedding; $D^{\prime}, I^{\prime}=$ declination and inclination after tectonic correction; $k=$ precision parameter; $\alpha_{95}=$ half angle of the $95 \%$ confidence circle about the mean direction; a.t.c. $=$ after tectonic correction; b.t.c. $=$ before tectonic correction.

\begin{tabular}{|c|c|c|c|c|c|c|c|c|c|c|c|}
\hline Site & Treat. & $N(\mathrm{l}, \mathrm{c})$ & $D$ & $I$ & $A$ & Dip & $D^{\prime}$ & $I^{\prime}$ & $k$ & $\alpha_{95}$ & Age \\
\hline $\mathrm{T} 2$ & Af & $10(7,3)$ & 194.6 & -54.2 & 235 & 19 & 167.5 & -65.8 & 23.68 & 10.3 & U. Pleistocene \\
\hline $\mathrm{T} 4$ & Af & $10(10,0)$ & 6.9 & 52.6 & & - & 6.9 & 52.6 & 39.58 & 7.8 & L. Pleistocene \\
\hline $\mathrm{T} 7$ & $\mathrm{Th}$ & $11(7,4)$ & 173.0 & -48.4 & & - & 173.0 & -48.4 & 197.9 & 3.3 & L. Pleistocene \\
\hline $\mathrm{T} 8$ & $\mathrm{Th}$ & $11(11,0)$ & 160.5 & -56.7 & 39 & 4 & 165.4 & -54.5 & 43.42 & 7.0 & L. Pleistocene \\
\hline T9 & Th & $8(8,0)$ & 166.2 & -68.6 & 72 & 2 & 171.2 & -68.4 & 246.6 & 4.3 & L. Pleistocene \\
\hline T10 & $\mathrm{Th}$ & $12(12,0)$ & 177.5 & -59.1 & & - & 177.5 & -59.1 & 134.5 & 3.8 & L. Pleistocene \\
\hline $\mathrm{T} 11$ & Th & $8(7,1)$ & 172.8 & -64.0 & 128 & 11 & 186.0 & -62.0 & 16.64 & 13.1 & L. Pleistocene \\
\hline $\mathrm{T} 15$ & Th & $7(2,5)$ & 354.4 & 62.1 & & - & 354.4 & 62.1 & 64 & 6.1 & L. Pleistocene \\
\hline T17 & Th & $6(0,6)$ & 1.08 & 62.0 & & - & 1.08 & 62.0 & 267.7 & 3.2 & L. Pleistocene \\
\hline \multicolumn{12}{|c|}{ Means } \\
\hline a.t.c. & (4 sites, & 36 specim) & & & & & 352.3 & 62.9 & 118.0 & 8.5 & \\
\hline b.t.c. & (4 sites, & 36 specim) & 354.6 & 61.6 & & & & & 64.1 & 11.6 & \\
\hline Total & (9 sites, & 75 specim) & & & & & 356.8 & 59.6 & 114.3 & 4.8 & \\
\hline
\end{tabular}




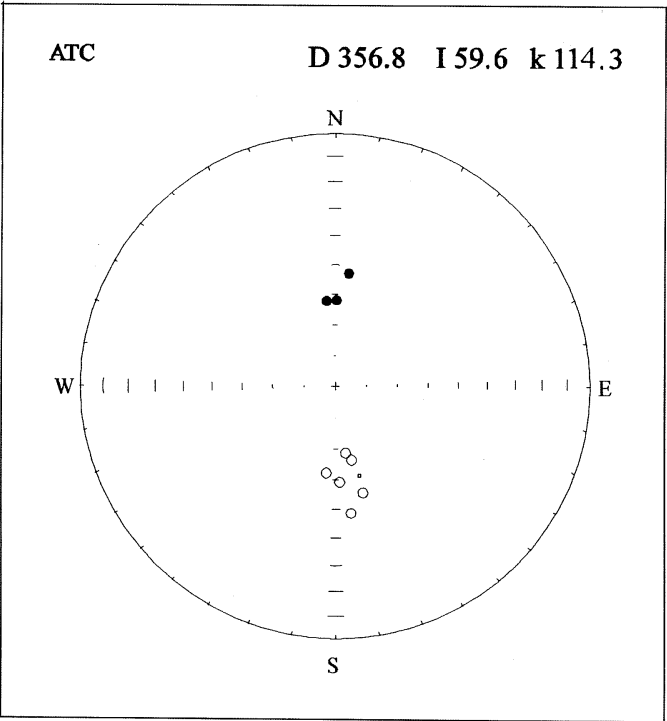

Fig. 5. Equal area projection of the site mean directions from all the measured sites (tilt correction was applied at the sites with appreciable dip of the bedding).

The stable components when reconducted to the upper (normal polarity) hemisphere were aligned with the present day Earth's magnetic field. At two sites it was possible to apply a tectonic correction. After tectonic correction the normal and reverse polarity site mean directions grouped into two antipodal clusters, giving a positive reversal test of type Rc of McFadden and McElhinny (1990). The ChRM mean directions of the nine sites reconducted to the lower (normal polarity) hemisphere after tilt correction were $D=356.8^{\circ}, I=59.6^{\circ}$, $\alpha_{95}=4.8, k=114.3$ (fig. 5, table II). The fold test was not performed due to the very low number of sites (T2, T11) having any appreciable bedding dip.

\section{Anisotropy of magnetic susceptibility results}

The mean susceptibility $\left(K_{m}\right)$ and the most common anisotropy factors (lineation $L=$ $=K_{\text {max }} / K_{\text {int }}$, magnetic foliation $F=K_{\text {int }} / K_{\min }$, corrected anisotropy degree $P^{\prime}$ and shape factor $T$, defined by Jelìnek, 1981) were computed (see table III). The measured anisotropy factors did not show significant between-site variations. The shape factor $T$ was always positive at all sites except $\mathrm{T} 12(T=-.475)$, at this site a prolate ellipsoid shape was observed. All the others sites showed oblate AMS ellipsoids and minimum susceptibility axes generally parallel to the bedding pole. $P^{\prime}$ range was $1.007 \leq P^{\prime} \leq$ 1.066. The $K_{m}$ showed relatively low values $\left(110 \times 10^{-6} \leq K_{m} \leq 311 \times 10^{-6} \mathrm{SI}\right)$; the higher values represented samples of the southern basin.

The semi-angle of the $95 \%$ confidence ellipse $\left(e_{12}\right)$ around the mean $K_{\max }$ direction in the $K_{\max }-K_{\text {int }}$ plane, allows the analysed samples to be divided in to two groups (e.g., table III):

a) Sites with $e_{12} \geq 30.0^{\circ}$ (T5, T8, T9, T11, T13, T14, T16, T17, T18).

b) Sites with $e_{12} \leq 30.0^{\circ}$ (T1, T2, T3, T4, T6, T7, T10, T12, T15).

Sites of group «a» showed either a very weak clustering (T9), or no clustering in terms of the the $K_{\max }$ axes; these sites are defined as «scattered». Sites of group «b» showed a well defined magnetic lineation given by the clustering of $K_{\max }$ axes in the bedding planes, these will be referred to as «clustered». The orientation of the magnetic lineations of the «clustered» sites and their distribution at each locality is shown by the arrows in fig. 1. A NE-SW trend of the $K_{\max }$ characterized two sites in the northern part of the Todi basin (T1, T2), as well as two sites in the Bastardo and Bevagna basins (T3, T4). Only one site (T15) in the northermost part of the Todi basin showed a NW-SE oriented magnetic lineation. N-S directions for the magnetic lineation were observed in the Southern Todi basin at five sites: T6, T7, T9, T10, T12. This latter group also included site T9 which, although belonging to the «scattered» group, showed a weak N-S oriented magnetic lineation (e.g., table III).

Differences between sites showing NE-SW and $\mathrm{N}-\mathrm{S}$ magnetic lineation respectively, were also enhanced by the mineralogical analyses. The predominant magnetic carrier at sites holding a NE-SW magnetic lineation was mag- 
Table III. List of anisotropy factors computed at each site. Arithmetic means of the individual specimen values as calculated by the ANS 21 program (Jelìnek, 1978). $N=$ number of samples; $K_{m}=$ mean susceptibility; $P^{\prime}=$ corrected anisotropy degree; $T=$ shape factor; see Hrouda (1982) for the mathematical expression of each factor. In bold face are reported sites referred as group «b» in the text. * = Sites with NE-SW magnetic lineation; \# = sites with $\mathrm{N}-\mathrm{S}$ magnetic lineation. $D=$ declination of the mean $K_{\max } ; I=$ inclination of the mean $K_{\max } ; e_{12}=$ semiangle of $95 \%$ confidence ellipse around the $K_{\max }$ direction in the $K_{\max }-K_{\text {int }}$ plane; the last two columns refer to data obtained after the magnetic cleaning.

\begin{tabular}{lcccccccc}
\hline \hline Sites & $N$ & $K_{m} 10^{-6}$ & $P^{\prime}$ & $T$ & $\begin{array}{c}D-I \\
K_{\max }\end{array}$ & $e_{12}$ & $\begin{array}{c}D-I \\
K_{\max }\end{array}$ & $e_{12}$ \\
\hline T1 ${ }^{*}$ & 10 & 198 & 1.066 & .870 & $225-11$ & $20^{\circ}$ & & \\
T2 & 10 & 196 & 1.015 & .720 & $227-12$ & $21^{\circ}$ & \\
T3 $*$ & 11 & 149 & 1.020 & .590 & $202-5$ & $18^{\circ}$ & & \\
T4 $*$ & 10 & 130 & 1.012 & .580 & $259-8$ & $18^{\circ}$ & & \\
T5 & 11 & 160 & 1.011 & .830 & $33-4$ & $51^{\circ}$ & & \\
T6 \# & 11 & 199 & 1.020 & .660 & $350-6$ & $21^{\circ}$ & $191-2$ & $35^{\circ}$ \\
T7 \# & 13 & 310 & 1.050 & .820 & $10-2$ & $12^{\circ}$ & $185-1$ & $26^{\circ}$ \\
T8 & 12 & 311 & 1.047 & .920 & $98-2$ & $30^{\circ}$ & & \\
T9 \# & 10 & 201 & 1.047 & .950 & $356-3$ & $35^{\circ}$ & $346-5$ & $51^{\circ}$ \\
T10 \# & 12 & 255 & 1.036 & .830 & $182-3$ & $11^{\circ}$ & $30-0$ & $82^{\circ}$ \\
T11 & 14 & 196 & 1.029 & .940 & $87-5$ & $80^{\circ}$ & & \\
T12 \# & 10 & 206 & 1.005 & -.470 & $167-8$ & $18^{\circ}$ & & \\
T13 & 8 & 155 & 1.048 & .950 & $281-4$ & $37^{\circ}$ & & \\
T14 & 8 & 137 & 1.048 & .850 & $92-6$ & $34^{\circ}$ & & \\
T15 & 10 & 145 & 1.007 & .030 & $146-7$ & $12^{\circ}$ & & \\
T16 & 9 & 166 & 1.053 & .960 & $55-1$ & $67^{\circ}$ & & \\
T17 & 9 & 112 & 1.011 & .510 & $194-1$ & $45^{\circ}$ & & \\
T18 & 11 & 184 & 1.012 & .880 & $175-1$ & $74^{\circ}$ & & \\
\hline Total & 189 & 189 & 1.029 & .692 & & & & \\
\hline & & & & & & & & \\
\hline
\end{tabular}

netite; iron sulphides were found as accessory minerals at only one locality (T2) out of four sites of the northern basin. Thermal demagnetisation of a composite IRM showed unblocking temperatures typical of magnetite (unblocking temperature of $580^{\circ} \mathrm{C}$ ), carried by the soft coercivity phase (fig. 6a, II). These same samples were completely saturated between 250-350 $\mathrm{mT}$, the coercivity of remanence values were around $-50 \mathrm{mT}$ (table III). The specimens showed closed hysteresis loops (see fig. 6a, III). Moreover, susceptibilities in low and high field had nearly the same value; in this case the low field anisotropy reflected the orientation of the matrix minerals (Richter and Van der Pluijm, 1994).

Iron sulphide minerals were the predominant magnetic carriers at four of the sites showing the N-S cluster of the $K_{\max }$ axes (T6, $\mathrm{T} 7, \mathrm{~T} 9, \mathrm{~T} 10$ ). The saturation of magnetisation was typically reached at $300-500 \mathrm{mT}$, coercivity of remanence values ranged from -50 up to $-100 \mathrm{mT}$ (table III). The ferrimagnetic phases for this group of samples showed maxi- 


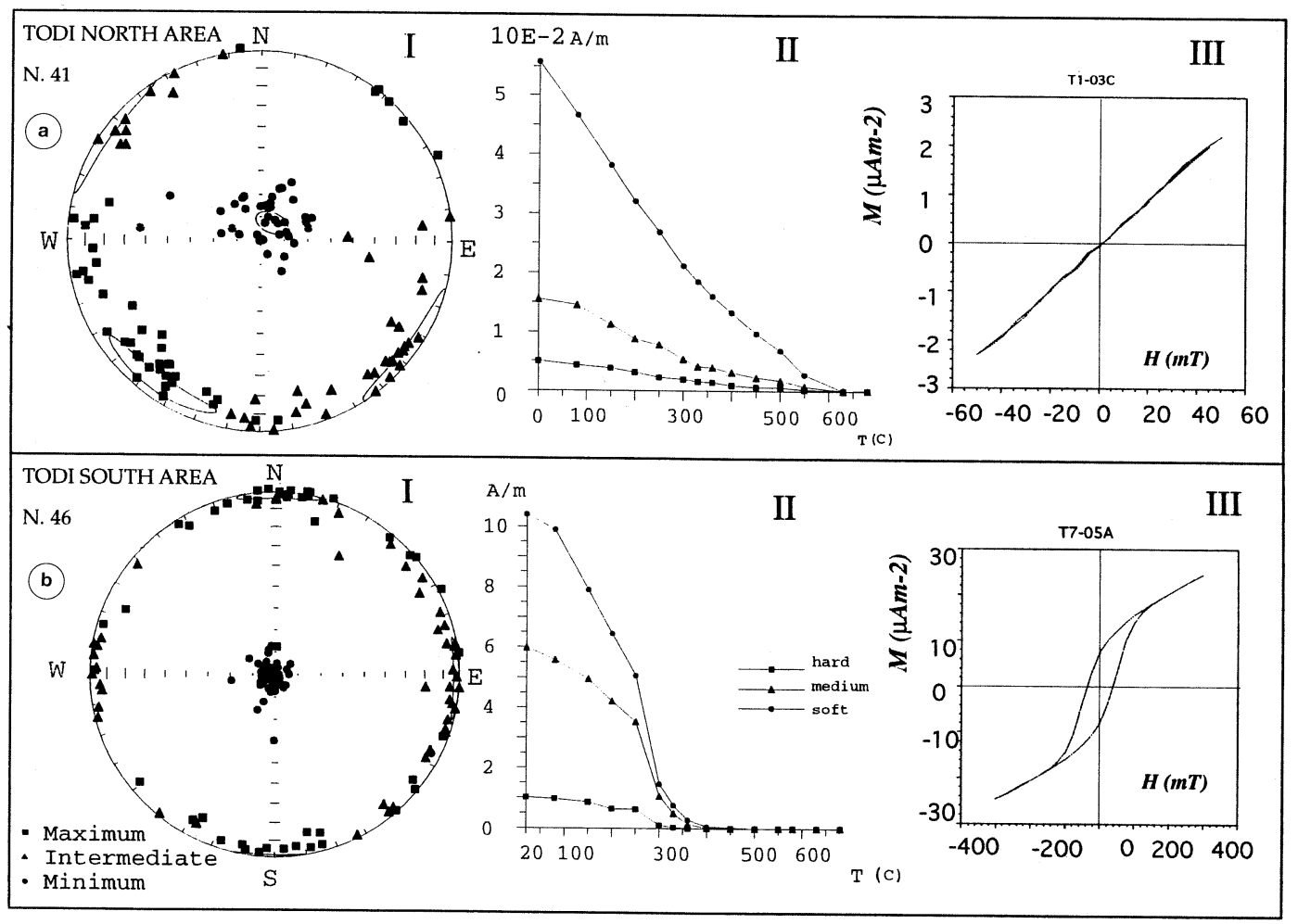

Fig. 6a,b. AMS and rock magnetic data for: a) the northern part of the basin, sites T1, T2, T3, T4; b) the southern part of the basin, sites T6, T7, T9, T10. I) Equal area stereonet showing the spatial distribution of the three principal axes of susceptibility; II) thermal demagnetisation of a three component IRM (see text for details) for a representative specimen; III) hysteresis loops for a representative specimen.

mum unblocking temperatures around $360^{\circ} \mathrm{C}$ (fig. 6b, II). At each heating step of the thermal demagnetisation of the composite IRM the low field susceptibility was monitored. Typically the susceptibility decreased between 200 and $300^{\circ} \mathrm{C}$. At two of the sites holding ironsulphides (T7, T10) the SIRM/ $k$ values were higher than in most natural magnetite assemblages. Low values of this parameter at the others sites holding iron-sulphides (T6, T9) may be attributed to the variability in iron-sulphide content through the sites. The set of samples containing iron-sulphides showed well defined hysteresis loops (fig. 6b, III). Site T12 instead, although showing a NNW-SSE to N-S magnetic lineation, likely of tectonic origin (e.g., $T$ value; table III), contained magnetite as main the magnetic carrier and no hysteresis loops resulted from this site.

In summary: the AMS and magnetic mineralogical analyses allowed the whole set of analysed samples to be divided into two main groups; one group was characterised by four sites with a NE-SW trend of the $K_{\max }$ axes (T1, $\mathrm{T} 2$, T3, T4), belonging to the northern part of the study area; at these sites magnetite was the main ferromagnetic carrier. The second set, sampled in the South Todi basin, showed a clear N-S magnetic lineation (T6, T7, T9, T10, T12). Iron-sulphides strongly characterised four sites of this second group: T6, T7, T9 and T10. The resulting hysteresis loops of these lat- 


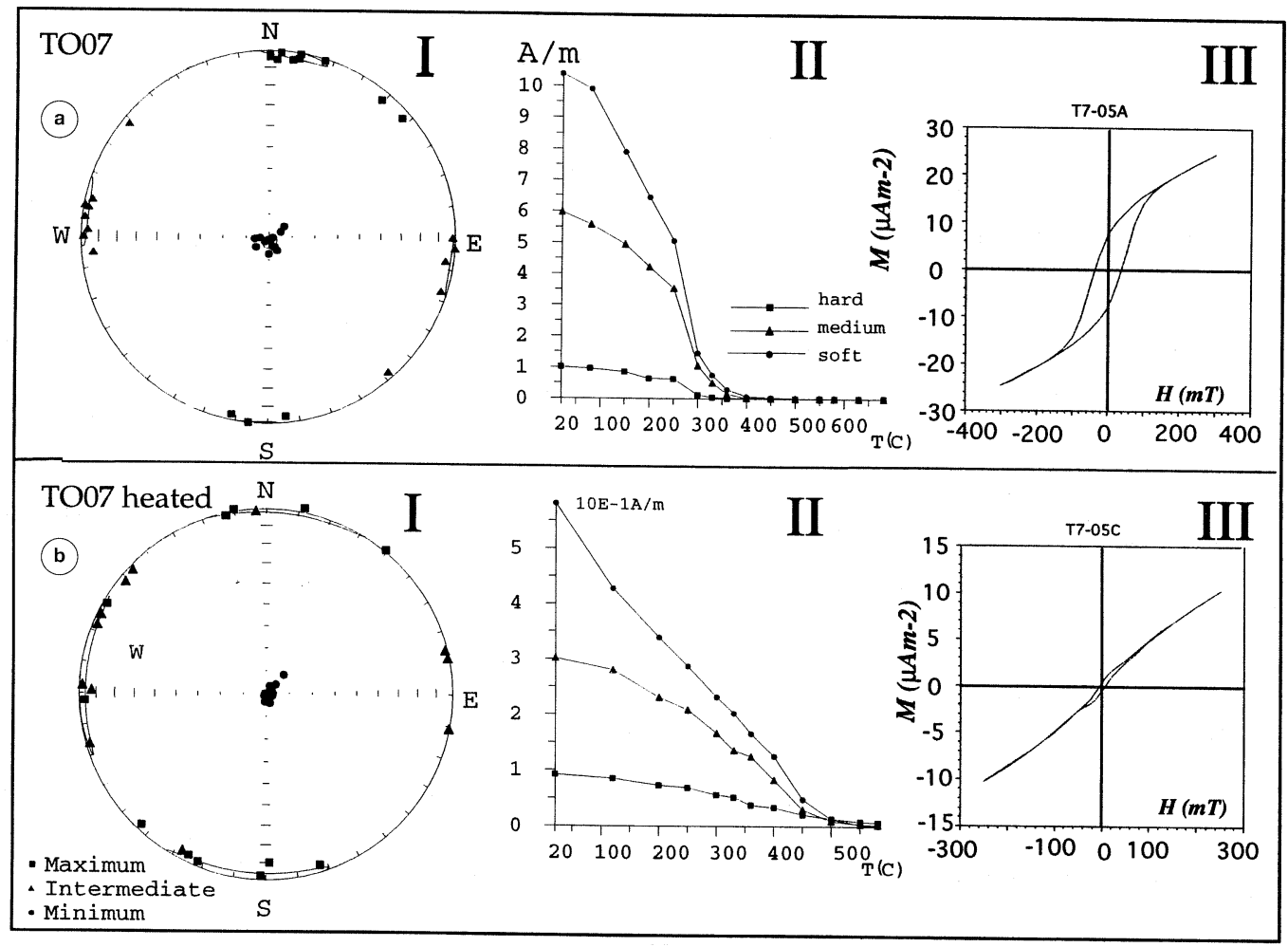

Fig. 7a,b. AMS and rock magnetic data for a representative site (T7), including from left to right: the stereonet showing the spatial ditribution of the three principal axes of susceptibility, the thermal demagnetisation of three orthogonal IRM for a representative specimen, and the hysteresis loops for a representative specimen. a) Before magnetic cleaning; b) after magnetic cleaning.

ter sites suggested that the AMS could be related primarily to the ferrimagnetic content (e.g., fig. 6b, III).

To investigate the role of the ferrimagnetic iron-sulphides on the N-S magnetic lineation, an experiment was performed. The samples holding this lineation and showing a major iron-sulphide content (T6, T7, T9, T10) were heated in steps up to a temperature of $380{ }^{\circ} \mathrm{C}$ $420{ }^{\circ} \mathrm{C}$, to demagnetise this magnetic phase. At each heating step the low field susceptibility was checked; the path of low field susceptibility versus temperature showed a linear decrease up to $420{ }^{\circ} \mathrm{C}$ indicating that new magnetic phases were not produced up to such temperature. After this thermal treatment the
AMS was measured again, as well as the magnetic properties of the heated samples (employing the same techniques described in the previous section). The results can be summarized as follows: 1) the AMS of the heated sites showed a reduced clustering of the maximum susceptibility axes, the N-S cluster disappeared after the cleaning process at two sites (T9, T10); however at sites T6 and T7 some N-S $K_{\max }$ orientation remained after the magnetic cleaning even though the corresponding ellipses of confidence were truly enlarged (see fig. 7a,b, II, and $e_{12}$ values table III); 2) the demagnetisation of a composite IRM performed after the heating process, pointed to magnetite as the remaining ferromagnetic carrier (fig. $7 b$, 
II); 3) nearly paramagnetic hysteresis loops resulted from the heated specimens (fig. 7b, III). The last two columns of table III illustrate the declination and inclination of the $K_{\max }$ axes and the $e_{12}$ values after heating for sites T6, T7, T9, T10.

The $e_{12}$ values obtained after heating showed the presence of a weak N-S oriented lineation at sites $\mathrm{T} 6$ and $\mathrm{T} 7$ while at sites $\mathrm{T} 9$ and T10 no clustering of the $K_{\max }$ axes results (e.g., table III). The iron-sulphides seemed to contribute robustly to the N-S cluster of the magnetic lineation at these sites. In particular at site T10 the N-S magnetic lineation seemed carried solely by the iron-sulphides, as the comparison of the AMS data and mineralogical analyses before and after the heating test showed (at this site the $e_{12}$ value obtained after the heating test is at random and clear paramagnetic hysteresis loops result). The fact that part of the N-S $K_{\max }$ direction stayed after heating at sites T6 and T7, is probably due to incomplete destruction of the sulphides. Perhaps a fair amount of the N-S magnetic lineation was also carried by other minerals, probably paramagnetic phases, at these sites.

\section{Discussion}

\subsection{Paleomagnetism}

The ChRM obtained from two sites in the Upper Pliocene (3.5-1.8 Ma), and eight sites in the Lower Pleistocene (1.8-1.1 Ma) sediments of the Todi and Bevagna basins, have a low dispersion. Both normal and reverse components of magnetisation were isolated. The normal component characterises three sites, Lower Pleistocene in age (T4, T15, T17); at these sites magnetite is the sole magnetic carrier. The reverse component was found at six sites, with ages ranging from Upper Pliocene to Lower Pleistocene (T2, T7, T8, T9, T10, T11). The principal magnetic carriers at sites with reverse component are iron-sulphides. Five specimens in this latter group showed another component of magnetisation, enhanced by remagnetisation circles, once the reverse component was removed (fig. 3c).
These latter specimens were dated as Lower Pleistocene (1.8-1.1 Ma).

The mean direction obtained from the intersection point of their remagnetisation circles (HT component) gives: $D=2.1^{\circ}, I=64.1^{\circ}$, $\alpha_{95}=0.6, k=6293$. The HT component shared the same mean direction of the overall ChRM; they both paralleled the Earth's magnetic field at the sampling localities. This latter point allows us to consider the sites at which two components of magnetisation were observed, to be still suitable for geodynamic purposes, although a remagnetisation in a period of reverse polarity field cannot be excluded for these samples. In this latter case the reverse component has to be acquired in a period between 1.8 and $0.78 \mathrm{Ma}$ as emerges from the stratigraphical age of the sediments (Lower-Pleistocene, 1.8-1.1 Ma) and the reverse component of this magnetisation. If this holds true, the age of the reverse component can be younger than the estimated stratigraphic age of the sediments, but unfortunately it cannot be better constrained at these two sites (T7-T11).

The positive reversal test indicates that the samples may be considered suitable for geodynamic purposes. The site mean direction can be considered to be the primary component of magnetisation, acquired in a period between 3.5 and $0.78 \mathrm{Ma}$. This overall mean direction is aligned with the expected Earth's geomagnetic field at the sampling localities $\left(D=0^{\circ}\right.$, $\left.I=60.5^{\circ}\right)$.

\subsection{Anisotropy of magnetic susceptibility}

In this study two well defined magnetic lineation directions were found in the Todi and surrounding basins. A NE-SW lineation characterises four sites distributed in the northern part of the Todi basin, and in the nearby Bastardo and Bevagna basins. The other lineation, $\mathrm{N}-\mathrm{S}$ trending, characterised five sites in the southern Todi basin.

The NE-SW magnetic lineation is orthogonal to the primary basin-bounding faults (fig. 1). It is parallel to the regional direction of the least compressive stress determined from borehole breakouts and seismic stress in- 
version (Montone et al., 1995). The NE-SW magnetic lineation is acquired in paramagnetic minerals and seems well correlated with the regional tectonics of the area. The N-S one instead is carried by paramagnetic phases at only one site (T12), while it is clearly influenced by ferrimagnetic iron-sulphides at the others. The $\mathrm{N}-\mathrm{S}$ lineation, on the other hand, shows no immediate geometric relation with the major features of the basin. The sedimentation in this latter part of the basin is linked to the presence of a deep lacustrine system characterised by gravitational process (Ambrosetti and Basilici, 1994). In this frame it is not likely that flood currents are recorded magnetically in these sediments.

Perhaps deformation coincident with the hydrothermal activity accounts for the N-S lineation found in the southern basin. If so, the iron-sulphide minerals may have grown in micro-cracks, probably E-W trending, that accompained the deformation and accomodated the hydrothermal flow.

As noted above, deposition of travertine throughout the Pleistocene and eruption of young volcanic rocks distinguish the Southern Todi basin from the other areas. This part of the basin was a thermal area then, as it is now. It is likely that the N-S magnetic fabric reflects the strain field that accomodated the pervasive hydrothermal circulation and mineral alteration probably occurring during the upper Matuyama chron between 1.8 and $0.78 \mathrm{Ma}$.

Localised mesostructural deformations such as fractures and joints in the South Todi basin have an E-W trend in agreement with a local direction of the least compressive N-S oriented stress. The E-W trending Cesi fault that bounds the southern border of the Martani ridge seems to affect the Lower Pleistocene cover of the S. Gemini area with its tensional mechanism (Brozzetti et al., 1991; and fig. 1 of this paper). If this holds true the stress field associated with this latter element may account for the $\mathrm{N}-\mathrm{S}$ magnetic lineation of the southern basin.

The two directions of the magnetic lineation found in the Todi extensional basin, seems linked to different processes; one is characteristic of the direction of the least compressive stress acting in the region since Plio-Pleis- tocene time, the other could reflect the existence of a more localised strain field restricted to the Southern Todi basin, but its origin has not been completely clarified.

\section{Conclusions}

The paleomagnetic results indicate no appreciable vertical axis rotation acting in the Todi basin since the Upper Pliocene time (3.5 Ma). This result agrees well with the paleomagnetic data obtained from the Tyrrhenian margin of Central Italy, where vertical axis rotations do not account for the Plio-Pleistocene tectonics of the area (e.g., Sagnotti et al., 1994). The Tyrrhenian Sea opening, responsible for severe lithosphere thinning and extension in the surrounding region, has not activated any block rotation mechanism in the peri-Tyrrhenian area as well as in the Todi basin since the Upper Pliocene. The Plio-Pleistocene extensional tectonics characterising the basin is probably linked to the same mechanism originating the Tyrrhenian Sea opening (Lavecchia and Stoppa, 1990). Expressions of these intense extensional processes are the calc-alkaline volcanic rocks outcropping in the area $(0.39 \mathrm{Ma})$. The extensional tectonics occurs on faults trending NW-SE; this NE--ENE direction of the least compressive stress dominates the Plio-Pleistocene tectonics of the Todi basin as well as the contemporary tectonics, as shown by in situ stress measurements (Montone et al., 1995).

The dominance of a NE--ENE direction of the least compressive stress is confirmed by the AMS results carried on the northern part of the Todi basin as well as in the Bevagna and Bastardo area. Here a characteristic NE-SW magnetic lineation was found which parallels the orientation of the regional least compressive horizontal strain of the area.

Instead, the southern part of the basin was characterised by a N-S trending magnetic lineation which does not directly match the regional tectonic or the sedimentary conditions of the area. In the paper we made the hypothesis that a late pervasive circulation of hydrothermal fluid, favoured by a set of E-W 
trending fractures accounts for such N-S magnetic lineation. This point was supported by the abundance of iron-sulphides in the samples of this part of the basin. Nevertheless a thermal destructive test carried on the samples holding iron-sulphides did not give a definitive and straightforward result. Iron-sulphides cannot be claimed as the only minerals responsible for the N-S trending lineation whose origin is still obscure.

Conclusively we can assert that block rotation mechanisms characterise the evolution of Neogene intra montane basins in the inner part of the Apennine chain (Sagnotti, 1992; Scheepers and Langerais, 1993; Mattei et al., 1995) but they do not seem to account for the structural evolution of the peri-Tyrrhenian region that instead is dominated by an extentional tectonic along NW-SE trending faults. The AMS data gave a further constraint in favour of this latter point.

\section{Acknowledgements}

This paper was reorganised following the critical advice of F. Heller and B. Henry. Leonardo Sagnotti and Luigi Vigliotti's suggestions improved the quality of this work. Fabio Florindo, Massimo Mattei and Laura Maschio helped during the field work. Tapan Mukerji kindly reviewed the English style.

\section{REFERENCES}

AifA, T., H. Feinberg and J.P. PozzI (1988): Plio-Pleistocene evolution of the Tyrrhenian arc: paleomagnetic determination of uplift and rotation deformation, Earth Planet. Sci. Lett., 87, 438-452.

Ambrosetti, P. and G. BASILICI (1994): I sedimenti continentali del bacino di Tavernelle e del ramo sud-occidentale del Bacino Tiberino, in Guide Geologiche Regionali, Soc. Geol. It., 91, 169-184.

Ambrosetti, P., A. Azzaroli, F.P. Bonadonna and M. FOLLIERI (1972): A scheme of Pleistocene chronology for the Tyrrhenian side of Central Italy, Boll. Soc. Geol. It., 91, 169-184.

Brozzetti, F., G. Lavecchia and F. Stoppa (1991): Presentazione di alcuni aspetti tettonico-strutturali e petrologici del distretto ultra-alcalino Umbro-Laziale, in Studi Geologici Camerti, Crop 11, special volume 1991/2.

Castellarin, A., C. Cantelli, A.M. Fesce, J.L. Mercier, V. Picotti, G.A. Pini, G. Prosser and
L. Selli (1992): Alpine compressional tectonics in Southern Alps. Relationships with the N-Apennines, Ann. Tectonicae, 6, 62-94.

CNR-Progetto Finalizzato Geodinamica (1989): Synthetic Structural-Kinematic Map of Italy, scale 1:20000.

Conti, M.A. and O. GirotTi (1977): Il Villafranchiano del «Lago Tiberino», ramo sud-occidentale: schema stratigrafico e tettonico, Geol. Romana, 16, 67-80.

De La Pierre, F., F. Ghisetti, R. LAnZa and L. VezZani (1992): Paleomagnetic and structural evidence of Neogene tectonic rotation of the Gran Sasso range (Central Apennines, Italy), Tectonophysics, 215, 335-348.

Dogloni, C. (1991): A proposal for the kinematic modelling of W-dipping subductions-possible applications to the Tyrrhenian-Apennines system, Terra Nova, 3, 423-434.

GraHAM, J.W. (1966): Significance of magnetic anisotropy in appalachian sedimentary rocks, in The Earth Beneath the Continents, edited by J.S. STEINHART and T.J. SMITH, Geophys. Monogr., 10, 627-648.

GREGORI, L. (1988): Il bacino di «Bastardo»: genesi ed evoluzione nel quadro della tettonica recente, Boll. Soc. Geol. It., 107, 141-151.

Hrouda, F. (1982): Magnetic anisotropy of rocks and its application in geology and geophysics, Geophys. Survey, 5, 37-82.

JACKSON, K.C. (1990): A paleomagnetic study of Apennine thrusts, Italy: Monte Maiella and Monte Raparo, Tectonophysics, 178, 231-240.

JELINNEK, V. (1977): The statistical theory of measuring anisotropy of magnetic susceptibility of rocks and its application, Geofyzika, Brno, pp. 87.

JELINEK, V. (1978): Statistical processing of anisotropy of magnetic susceptibility measured on groups of specimens, Stud. Geophys. Geod., 22, 50-62.

JELİNEK, V. (1981): Characterization of the magnetic fabric of rocks, Tectonophysics, 79, 63-67.

KIRSCHVINK, J.L. (1980): The least-square line and plane and the analysis of paleomagnetic data, Geophys. J. R. Astron. Soc., 62, 699-718.

Kissel, C., E. BARrier, C. LAJ and T.Q. LeE (1986): Magnetic fabric in «undeformed» marine clays from compressional zones, Tectonics, 5, 769-781.

KLIGFIELD, R., W.H. OWENS and W. LowrIE (1981): Magnetic susceptibility anisotropy, strain and progressive deformation in Permian sediments from the Maritime Alps (France), Earth Planet. Sci. Lett., 55, 181-189.

Lavecchia, G. and F. Stoppa (1990): The Tyrrhenian zone: a case of lithosphere extension control of intracontinetal magmatism, Earth Planet. Sci. Lett., 99, 336-350.

LeE, T.Q., C. Kissel, C. LAJ, C.S. HoRnG and Y.T. Lue (1990): Magnetic fabric analysis of the Plio-Pleistocene sedimentary formations of the Coastal Range of Taiwan, Earth Planet. Sci. Lett., 98, 23-32.

LOWRIE, W. (1989): Magnetic analysis of rock fabric, in Encyclopedia of Solid Earth Geophysics, edited by D.E. JAMES (Van Nostrand Reinhold, New York), 698-706. 
LOWRIE, W. (1990): Identification of ferrimagnetic minerals in a rock by coercivity and unblocking temperature properties, Geophys. Res. Lett., 17 (2), 159-162.

LOWRIE, W. and A.M. HIRT (1987): Anisotropy of magnetic susceptibility in the Scaglia Rossa pelagic, Earth Planet. Sci. Lett., 82, 349-356.

MARTON, P. and M. D'Andrea (1992): Paleomagnetically inferred rotations of the Abruzzi and Northwestern Umbria, Tectonophysics, 202, 43-53.

Mattei, M., R. Funiciello and C. Kissel (1995): Paleomagnetism and structural evidence for Neogene block rotations in the Central Apennines, Italy, J. Geophys. Res., 100 (B9), 17863-17883.

McFadden, P.L. and M.W. MCELhinny (1988): The combined analysis of remagnetisation circles and direct observations in paleomagnetism, Earth Planet. Sci. Lett., 87, 161-172.

MCFADDEN, P.L. and M.W. MCELhinny (1990): Classification of the reversal test in paleomagnetism, Geophys. J. Int., 103, 725-729.

Montone, P., A. Amato, C. Chiarabba, G. BuonaSORTE and A. FIORDELISI (1995): Evidence of active extension in Quaternary volcanoes of Central Italy from Breakout analysis and seismicity, Geophys. Res. Lett., 22 (14), 1909-1912.

Parotto, M. and A. Praturlon (1975): Geological summary of the Central Apennines, in Structural Model of Italy, edited by L. OGNiBen, M. PARotTo and A. PrATURlon, Quad. Ric. Sci., 90, 257-311.

Patacca, E., R. SArtori and P. Scandone (1990): Tyrrhenian basin and Apennine arcs: kinematic relations since late Tortonian times, Mem. Soc. Geol. It., 45, 425-451.

RICHTER, C. and B.A. VAN DER PluiJM (1994): Separation of paramagnetic and ferrimagnetic susceptibilities us- ing low temperature magnetic susceptibilities and comparison with high field methods, Phys. Earth Planet. Inter., 82, 113-123.

Roberts, A.P. and B.J. PILlans (1993): Rock magnetism of Lower/Middle Pleistocene marine sediments, Wanganui basin, New Zealand, Geophys. Res. Lett., 20, 839-842.

SAGNOTTI, L. (1992): Paleomagnetic evidence for a Pleistocene counter-clockwise rotation of the Sant'Arcangelo basin, Geophys. Res. Lett., 19, 135-138.

SAGNOTTI, L. and F. SPERANZA (1993): Magnetic fabric analysis of the Plio-Pleistocene clayey units of the Sant'Arcangelo basin, Southern Italy, Phys. Earth Planet. Int., 77, 165-176.

Sagnotti, L., M. Mattei, C. Faccenna and R. FuniCIELLO (1994): Paleomagnetic evidence for no tectonic rotation of the Central Italy Tyrrhenian margin since Upper Pliocene, Geophys. Res. Lett., 21 (6), 481-484.

SCHEEPERS, P. and C.G. LANGERAIS (1993): Analysis of the NRM directions from the Rossello composite: implications for the tectonic rotation of the Caltanissetta basin, Sicily, Earth Planet. Sci. Lett., 199, 243-258.

SNOWBALL, I.F. (1991): Magnetic hysteresis properties of greigite $\left(\mathrm{Fe}_{3} \mathrm{~S}_{4}\right)$ and a new occurrence in Holocene sediments from Swedish Lappaland, Phys. Earth Planet. Inter., 68, 32-40.

TARLING, D.H. and F. HroudA (1993): The Magnetic Anisotropy of Rocks (Chapman and Hall, London), pp. 217.

(received April 3, 1997; accepted December 22, 1997) 